\title{
ROHKEM KUI SÕNAD
}

\section{Jaakko Lehtonen}

Ülevaade. Artikkel julgustab rakenduslingviste lisama verbaalse keele uurimise paradigmasse visuaalse keele mudelid ja teooriad, kaasama visuaalset kompetentsi, visuaalse kirjaoskuse ja ladususe küsimusi diskussiooni lingvistilise kompetentsi, kirjaoskuse, ladususe jms üle. Kommunikatsiooni visuaalseid elemente kohtab kõige enam reklaamikontekstis. Arvatakse, et reklaamide visuaalsed kujutised (visuaalid) parandavad suhtumist brändi ning mõjutavad positiivselt käitumiskavatsusi. Artiklis käsitletakse visuaalide mõningaid aspekte keele ja kommunikatsiooni vaatenurgast ning antakse lühiülevaade neuroökonoomika ${ }^{2}$ neist tulemustest, mis on saadud magnetresonantsuuringute (Magnetic Resonance Imaging ehk MRI) toel.

Võtmesõnad: kirjaoskus, reklaam, veenmine, visuaalne keel, visuaal, MRI

\section{Sissejuhatus}

Reklaam on kõikjal. Meid ümbritsevad iga päev sajad reklaamsõnumid, rääkimata varjatud sõnumitest, mis võivad peituda kus tahes. Reklaamid töötavad sotsiaalse reaalsuse pinnal. Nad soovitavad meile, mida süüa, kuidas riietuda, kuidas veeta vaba aega, seega pakuvad meile valikuid igaks elujuhtumiks. Me ei suuda põgeneda reklaamide loodud sotsiaalse maailma eest, sest see on kõikvõimas ja kõikjal meie ümber.

Sõnumit, mis on mõeldud mõjutama isiku arvamusi, emotsioone, hoiakuid ja käitumist, kutsutakse veenmiseks. Artiklis on vaatluse all kahte tüüpi veenmisaktid - propaganda ning kommerts- ja sotsiaalreklaam, kusjuures keskendutakse reklaamikommunikatsiooni visuaalsetele elementidele. Uuemad teadmised, mis on saadud brändireklaamide vaataja ajufunktsioonide salvestamisel magnetresonantsuuringutes (MRI), lubavad oletada, et visuaalne sõnum võib mõjutada ajutalitust ja alateadlikult ka meelelist taju, kuid võimalik et ka inimese käitumist.

\footnotetext{
1 Pealkiri on laenatud Richard Dimbleby, Graeme Burtoni õpikust "More than Words. An Introduction to Communication", London: Routledge, 1992.

2 Neuroökonoomika (ingl neuroeconomics, eesti keeles sageli neuroökonoomika) on majandusteaduse interdistsiplinaarne allvaldkond, mis ühendab neuroteaduse, ökonoomika, psühholoogia ja mille eesmärk on uurida aju rolli otsuste tegemisel majanduskeskkonnas.
} 
Et näidata visuaalide tähtsust inimtunnetuses, käsitletakse artiklis nende mõningaid aspekte keele ja kommunikatsiooni kontekstis, samuti antakse lühiülevaade MRI tulemustest.

\section{Visuaalide uurimiskontekst}

Rakenduslingviste huvitab eelkõige reklaamis ja visuaalses propagandas kasutatav veenmiskeel ja selle grammatika. Kas visuaalse keele n-ö sõnad on universaalsed, s.o samad kõigi jaoks, või tõlgendatakse veenmissõnumeid eri maades erinevalt; kas visuaalid mõjutavad ühtviisi eestlasi, ameeriklasi ja soomlasi? Kui ei, siis milline on kultuuri mõju reklaami tähendusele? Äsja käivitunud rahvusvahelise projekti esialgsed tulemused lubavad oletada, et erinevus selles, mida eri maade inimesed näevad ühes ja samas reklaamis, võib olla isegi suurem kui juleti oodata. ${ }^{3}$

Reklaami kogumahust moodustab tekst enamasti ainult väikese osa. Enamikus reklaamides kannab põhiinfot visuaalne kujutis. Mõnes reklaamis ei esine keelelist teksti üldse, teistes esinevad sellised verbaalse keele elemendid nagu ettevõtete logod või tootenimed, kuid hoopis visuaalidena. Visuaalne kujutis on kommertskommunikatsiooni põhielement, kuid ometigi peatume harva reklaami ees, et n-ö lugeda teadlikult pildi tähendust - mida üldse pildiga öeldakse või mis sõnumit tahab reklaamija meile lähetada, kasutades just sellist pilti.

Kui visuaalsed kujutised on nii olulised, siis miks ei ole uurijad jõudnud sügavamate teadmisteni visuaalidest ja nende toimimisest? Val Larseni, David Luna ja Laura A. Peracchio (2004) järgi eksisteerib lõhe, mis eraldab kahte akadeemilist kultuuri: mentaalseid protsesse ja visuaalsetele stiimulitele reageerimist uurib eksperimentaalpsühholoogia, reklaami tähendust aga põhiliselt lingvistika ja semiootika. Tarbijareageeringu empiirilise testimise puudumine mõlemas neis on kahandanud tulemuste praktilist paikapidavust.

Lisaks keskendub enamik lingvistika ja semiootika reklaamiuurimusi sellele, kuidas keele abil antakse edasi reklaampakkumise sisu. Kui visuaalsete kujutiste üle on üldse arutletud, siis on neid käsitatud kui reklaami illustratsioone. Sarnasust võib näha illustreeritud lasteraamatutega: raamatu põhiline väärtus seisneb piltides, kuid see, kes kirjutab piltide juurde paar värsirida või väikse teksti, on kaanel märgitud autoriks ning kunstniku nime leiab väiksemate tähtedega tema nime alt: Illustreerinud NN.

Tähenduse analüüsi või visuaalse kommunikatsiooniga on seotud veel üks probleem. Visuaalide analüüsimiseks kaldutakse nende tähendust ümber kodeerima lingvistiliseks koodiks, implitsiitselt oletades, et visuaalset sõnumit saab verbaalsesse keelde tõlkida. Kuid mis oleks siis, kui tähendus, mida pilt kannab, on aisting, maitse, õhkkond, midagi mida isik kogeb, kuid mida otseselt verbaalsesse keelde tôlkida ei saa?

Loomulikult on tarbijad üle maailma võimelised n-ö lugema pilte, kuid kas nad loevad samas keeles? Naiivoletuse kohaselt on piltide tähendused universaalsed. Pildid on - vastavalt sellele tõekspidamisele - nagu visuaalne esperanto, keel, mis ületab kõik keele- ja kultuuribarjäärid.

Säärase tõekspidamise pooldajad kasutavad sama sõnumit igas kultuuris. Nad esitavad väljakutse väitele, et eri kultuuride turg on erinev. Teised osutavad rahvuste

3 2006. a käivitunud projektis, mida juhivad dr Dessislava Boshnakova New Bulgarian ülikoolist ja dr Jaakko Lehtonen Jyväskylä ülikoolist, kogutakse reaktsioone reklaamikollektsioonile, intervjueerides eri kultuuride tarbijaid. Esimesed andmed koguti 2006. a Bulgaariast, Soomest, Ukrainast ja Šveitsist. 
erinevustele elustiilis, kollektiivsetes väärtustes, majandusliku arengu tasemes ning kultuuris tervikuna, nad tahavad kohandada oma sõnumit iga kultuuri jaoks ning luua erinevaid sõnumeid, et rahuldada iga kultuuri ootusi.

Reklaamija, kes esindab n-ö standardiseerimise koolkonda, valib reklaami pildikujundi lähtuvalt sellest, kuidas sihtauditoorium tema enda kultuuris tõenäoliselt visuaalset sõnumit dekodeerib, oletades, et sihtkultuuri tarbija teeb seda samamoodi. Võib-olla talitas sellest seisukohast lähtudes ka reklaamija, keda kirjeldab Øyvind Dahl (2001): too avaldas araabia maades peavalutablette reklaamiva koomiksi, ent reklaamitavatel tablettidel oli kehv menu. Vasakpoolsel koomiksipildil oli kujutatud kannatava ilmega inimest, keskmisel pildil võttis ta tableti sisse ja paremal pildil naeratas, ilmselgelt ilma mingi peavaluta. Reklaamija ei pööranud aga tähelepanu sellele, et araabia tekste loetakse paremalt vasakule. Mitte keegi ei tahtnud osta tablette, mis põhjustavad peavalu!

Visuaalsete kujutiste uurimise teoreetilist raamistikku on nimetatud visuaalseks retoorikaks, et eristada seda verbaalse keele tähenduste teooriast. Visuaalne retoorika erineb visuaalse kunsti uurimisest - või reklaami visuaalse graafilise disaini uurimisest, milles keskendutakse esteetilistele kaalutlustele. Visuaalne retoorika uurib kultuurilisi tähendusi, mis väljenduvad visuaalsetes artefaktides, nagu maalid, fotod, reklaamid, võrgulehed või ajalehed. David Blakesley (2006) järgi on näiteks visuaalne retoorika kokku kleebitud standardse arusaamaga retoorikast kui keelelisest veenmiskunstist. Lisaks sellele õpetavad retoorika käsiraamatud, kuidas kasutada visuaalset materjali, et täiendada ja avardada verbaalse keele argumente, või kuidas kasutada visuaalset materjali illustratsioonina, või lihtsalt kuidas kasutada ära publikatsiooni küljendust.

Visuaale ja kultuuri uurib ka visuaalne antropoloogia. See on sotsiokultuurilise antropoloogia allvaldkond, mis hakkas arenema pärast kino ja fotograafia teket. Kuigi öeldakse, et visuaalne antropoloogia hõlmab massimeedia tootmist ja vastuvõtmist, on keskmes massimeedia toote antropoloogiline uurimine, mitte aga näiteks visuaalsete märgitähenduste kultuuridevaheline võrdlemine (vt Lester 1999).

\section{Visuaali kasutuskontekst}

Veenmine ei peitu mitte ainult pildis, vaid sõltub mentaalsetest protsessidest, mida pilt kontekstuaalsete, situatsioonist lähtuvate ja individuaalsete muutujate mõjul inimese peas esile kutsub. Tänapäevast, sotsiaalses keskkonnas toimuvat veenmist võib teisalt nimetada võistlevaks veenmiseks: meile pakutakse rohkem kui ühe elustiili võimalust, rohkem kui üht poliitilist kandidaati või brändi, ja igaüks neist pommitab meid pidevalt ja püüab veenda enda eelistes. Uurimust, mis keskendub unikaalsetele visuaalsetele aspektidele reklaaminduses, nimetatakse visuaalseks veenmiseks. Reklaaminduses, nagu ka propagandas võib pilte kasutada muuhulgas selliste väidete esitamiseks, mis muidu oleksid vastuvõetamatud või mida verbaalselt esitatuna tõrjutaks tagasi.

Vastupidiselt kultuurispetsiifikat ignoreeriva standardiseerimise koolkonna veendumusele, millest eelpool juttu oli, võib esitada hüpoteesi, et eksisteerib visuaalne keel, mis varieerub kahe erineva kultuuri piires samamoodi nagu verbaalne keel. 
Uurimusi kultuurierinevustest visuaalide n-ö lugemises on üsna vähe. Verbaalset veenmist on uuritud sajandeid, mille tulemusel on tekkinud kõrgetasemelised mudelid ja teooriad, kuid visuaalse veenmise uurimine on alles lapsekingades. Visuaalse kommunikatsiooni teooria on lähedalt seotud semiootikaga. Pilte võib vaadata ikoonilisuse ja indeksilisuse vaatenurgast. Esimene viitab pildi võimele imiteerida reaalsust: inimesed võivad näha pilti sümbolina, mis justkui (taas)loob reaalsust. Indeksilisus viitab pildile, mida nähakse kui füüsilise reaalsuse füüsilist jäljendit: inimesed võivad näha pilte nii, nagu need oleks reaalsuse vahendamata jäädvustused, selle vahetu osa. Need semiootika mõisted on hiljuti toodud reklaamiuurimisse vägagi huvitaval moel: brändi ikoonistaatus on alati olnud eduka brändiloome peasiht, mida on nimetatud kultuuriliseks brändiloomeks. Niisuguse brändiloome näitena on ikooniks muutunud Coca-Cola. Douglas B. Holti (2004) järgi viivad brändi ikooni staatusesse lood tema kasutuselevõtust ja identiteedimüüdid. Nii aitas Coca-Colat kultuurilise ikooni staatusesse tõsta teadmine, et seda jõid Ameerika sõdurid Teise maailmasõja ajal.

Enne piltide veenmisjõu käsitlemist peatun korraks tähenduse ja kultuuri küsimusel. Tegelikult on küsimus pildi tähenduse kultuurilisest seotusest puhtakadeemiline. Kõik teavad igapäevakogemuse põhjal, et igas kultuuris on sõnumeid, ja mitte ainult pilte, mida teisest kultuurist pärit inimene ei mõista või millest saadakse aru täiesti erinevalt.

Ron Allison (1995) toob näiteid eksimustest mõnede reklaamlausete (ingl slogan) tajumisel kultuuride kommunikatsioonis:

\author{
Lähtesõnum \\ "Come alive with Pepsi!" \\ "Schweppes tonic water" \\ "Cleans the really dirty parts of you wash"
}

\begin{abstract}
Vastuvõetud sõnum
Sakslaste tõlgendus: "Come out of your grave with Pepsi" 'Tule välja oma hauast koos Pepsiga'

Itaallaste tõlgendus: "Schweppes bathroom water" 'Schweppes vannivesi'

Kanada prantslaste tõlgendus: "Cleans your private parts!" 'Puhastab su privaatsed kehaosad'
\end{abstract}

Sarnast vääritimõistmist võib kohata ka visuaalses kommunikatsioonis, kuigi seal on raskem avastada momenti, millal pildi tähendust vääriti mõistetakse. Võib-olla on mõned meist seisnud võõral maal WC-ukse taga ja üritanud nuputada, kumb sümbol tähistab meest ja kumb naist. Vahel aga tehakse väär otsus mitte pildi, vaid väärtuste tasandil. Mõni aeg tagasi üritas anonüümne Soome mobiilitootja müüa telefone Hiinasse reklaamiga, kus telefoni käes hoidev mees seisab üksinda suurel inimtühjal mäel. Kavatsetud sõnum oli “Mobiiltelefoniga pole sa kunagi üksi”, kuid hiinlased ei tahtnud seda telefoni, sest kartsid sattuda niisugusele tühermaale, kus pole ühtegi teist inimolevust (vt Li 2001).

Kultuuri ja visuaalide seotust demonstreerivad järgmised joonised. Igaüks teab väikesi mehikesi valgusfooris (vt joonis 1). Mõned võivad ära tunda, et need mehikesed on võetud Ida-Berliini valgusfooridest, Lääne pool on kujud kõhnemad. Kuid kui me ei teaks konteksti, milles neid kujusid nähakse, või millest nende punane ja roheline värv meile märku annab, siis oleksid need mehikesed lihtsalt seisva ja kõndiva mehe pildid. 

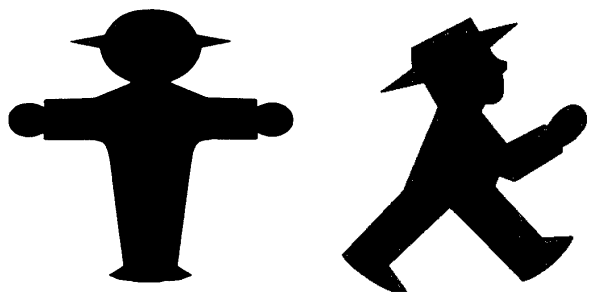

Joonis 1. Jalakäijate valgusfoori tuled, vasakpoolne mehike on punane, parempoolne roheline

Poliitilisel karikatuuril on väike merineitsi riietatud islami burkasse (vt joonis 2).

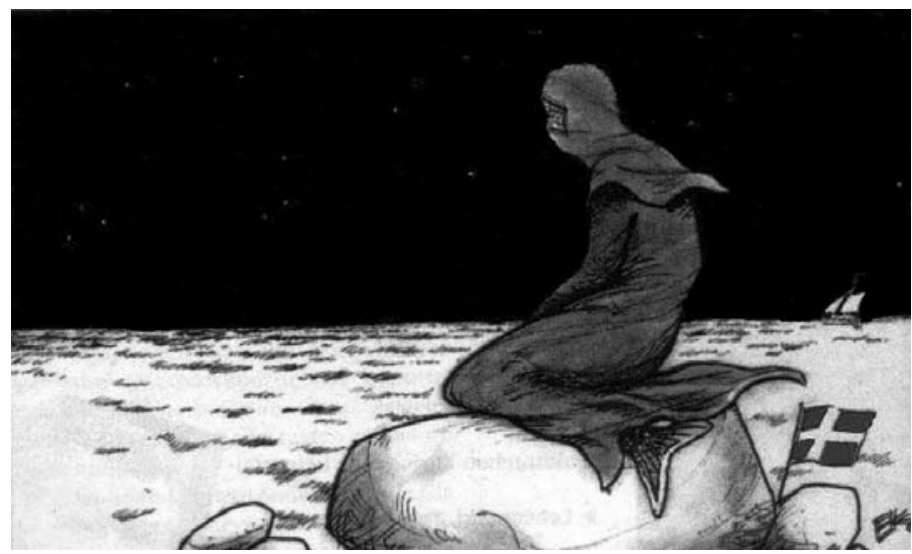

Joonis 2. Merineitsi (Suomen Kuvalehti 10.2.2006)

Sellest pildist arusaamine nõuab nii kultuurilist kui sotsiaalset teadmist ning metafoori mõistmist. Tuleb teada, et Merineitsi on Kopenhaageni sümbol ja et Taani ajaleht avaldas koomiksipildid Muhamedist, mis tekitasid ulatusliku meeleavalduste laine islamimaades. Visuaalset kirjaoskust vajatakse ka pildi metafoorse tähenduse mõistmiseks: Lääne muret selle üle, et islam levib Euroopasse.

Joonis 3 sisaldab palju sümboolset ja metafoorilist.

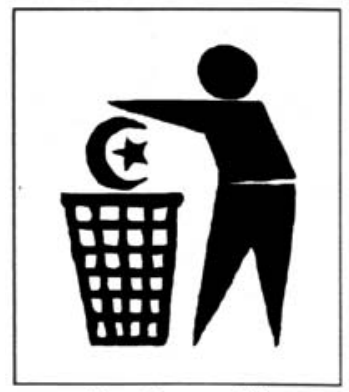

Keep Europe Tidy

Joonis 3. Hoia Euroopa puhas 
Selleks et sõnumist aru saada, tuleb teada prügikasti-mõistet ning millegi prügikasti viskamise metafoori. Et anda metafoorile tähendust, tuleb teada islami sümboleid, aga ka ajaloolist konteksti, milles joonistus avaldati.

Kaks nendest lihtsatest piltidest on visuaalse propaganda näited: nii merineitsi kui ka prügikast kannavad poliitilist sõnumit, islamivastasust. Enamikule eurooplastele on sõnum ilmselge, ja seda ilma ühegi verbaalse sümbolita mis tahes keeles.

Kuid kas pildid saavad käituda visuaalse veenmise, propaganda või isegi ajupesuvahendina? Uus tekkiv teadusharu - neuroökonoomika - üritab avada Pandora laegast ning paljastada, mis toimub inimajus, kui tarbija näeb pilte ning teeb ostuvalikuid, ehk teisiti öeldes, milline on inimese mentaalne seisund ning reaktsioon turundussõnumitele. (Vt ka Braeutigam 2005.)

\section{Aju-uuringud}

Neuroökonoomika kasutab ajutegevuse uurimiseks järjest enam magnetresonantsuuringuid, millega on võimalik ohutult saada pilte aju aktiveerunud piirkondadest (vt Economist 12.6.2003).

Esimesed MRI-meetodil tehtud avastused visuaalide uurimises saavutasid laia kõlapinna. Autohuviliste meestega tehtud katsetest selgus, et nende aju mõnupiirkond aktiveerub sportautode pilte nähes märgatavalt enam kui limusiini või väikeautode piltide puhul. Sellest võib järeldada, et aju mõnupiirkondi on võimalik aktiveerida toodete abil, mis assotsieeruvad rikkuse ja sotsiaalse positsiooniga (Erk jt 2002).

Veelgi enam erutas aga turundusinimesi Baylori Meditsiinikolledžis läbiviidud MRI-katse kahe hästituntud suhkrujoogi Coca-Cola ja Pepsiga (vt McClure jt 2004). Mõlemad joogid on väga sarnase keemilise koostisega, ent tarbijad jagunevad selgelt kaheks, ühed on veendunud Coca-Cola pooldajad ja teised eelistavad Pepsit. Korraldati kaks katset, esimeses tuli katsealustel juua kahte jooki, ilma et nad oleksid teadnud, kumb on kummas klaasis, ning neil tuli öelda, kumba nad peavad maitse põhjal paremaks. Teises katses uuriti brändi mõju eelistuse kujunemisele: kuigi näiteks mõlemas klaasis oli ainult Coca-Cola või ainult Pepsi, kandis üks neist Coca-Cola tunnust ja teine Pepsi oma.

Tulemustest selgus, et pimekatse puhul ei lähe aju reageering kokku selle joogiga, mida katsealused olid öelnud end eelistavat. Katses maitselt paremaks peetud jook aktiveeris ajus ventromediaalse prefrontaalse korteksi (VMPFC).

Teises katses, kus katsealused arvasid teadvat, mida nad joovad, aktiveerusid Coca-Cola fännidel selle sildiga jooki juues mitmed ajupiirkonnad: hipokampus, dorsolateraalne prefrontaalne korteks (DLPFC), keskaju, talamus ja ajukoore vasak nägemispiirkond. Pepsi silt sellist aktiveerumist esile ei kutsunud. Katsetest järeldus, et sensoorne info määrab inimese käitumist vaid osaliselt ja eelistusotsuste tegemisel on suur roll bränditeadlikkusel.

Katse on heaks illustratsiooniks sellele, kuidas lähetatud reklaamsõnum võib tõepoolest töötada alateadvuse tasandil, ning kuidas visuaalsete sümbolitega saab valla päästa reaktsioone. Bränd on võimeline petma aju nii, et see modifitseerib maitseneuronitega vastuvõetud informatsiooni! 
Kuigi neuroturundus (vt Lee jt 2007) teeb alles esimesi samme, on selle hirmuäratavad võimalused poliitilises propagandas ja kahjulike toodete ning harjumuste reklaamimises (nt tubakas, alkohol, isegi narkootikumid) esile kutsunud kriitikat. Commercial Alert, Ameerika tarbijate assotsiatsioon saatis 12. juulil 2004 Ameerika Ühendriikide Kaubanduskomiteele kirja, nõudes neuroturunduse asjas juurdlust. Assotsiatsioon küsib: "Mis juhtub sellel maal, kui korporatiivsed turustajad ja poliitilised konsultandid võiksid sõna otseses mõttes piiluda meie ajusse ning kaardistada närvitegevuse, mis suunab meid tegema valikuid supermarketites ja valimiskabiinides? Mis juhtub, kui nad saaksid närvikava aktiveerida, et muuta meie käitumist vastavalt nende vajadustele?”

Neuroökonoomika uurimistulemused näivad toetavat ka nüüdisaegse reklaaminduse väidet, et reklaam mõjutab tarbijat enim siis, kui ta sellele ei mõtle. Kuigi inimesed võib-olla ei pööra reklaamidele tähelepanu või ei mõtle neile teadlikult, imab aju keskkonnast pidevalt informatsiooni. Kuid me ei vaja neuroteaduse tõestusi märkamaks, et reklaamindus on propaganda haru, mis keskendub kommertstoodete ja teenuste üleskiitmisele - vastupidi poliitilisele propagandale, mis teostab valitsuste, poliitiliste parteide ja kolmanda sektori eri laadi organisatsioonide avalikke informatsioonikampaaniaid. Meetodid on samad: slogan'id, stereotüpiseerimine, veenvad tõendid, autoriteetidele viitamine, kuulsustest toetajate kasutamine, eufooria, lärmakad orkestrivankrid, must-valged valikud jne. Neid vahendeid võib kohata nii poliitilises reklaamis kui ka kommertspropagandas, nii verbaalses kui ka visuaalses keeles. Visuaalse turunduskommunikatsiooni rahvuslike vm kultuuriliste karakteristikute ja kultuurivastuolude uurimine on väljakutse kultuuride kommunikatsiooni rakendusuuringutele. Kuigi me võib-olla ei leiagi osta-nuppu, millest unistab neuroturundus, võime siiski õppida nii mõndagi visuaalsest veenmisest. Vähemalt õpime paremini aru saama sellest, kuidas inimene töötleb visuaalset informatsiooni - ja pürgimus aru saada inimese käitumisest on alati olnud ja jääb kõikide inimuuringute põhieesmärgiks.

\section{Kokkuvõte}

Kommunikatsioon tähendab palju enamat kui verbaalse keele kasutamist. Visuaalsed kujutised esindavad lühimat teed inimajusse. Nii turunduses kui ka tarbijapsühholoogias tehtud uurimused on kinnitanud visuaalide jõudu kommertslikus ja poliitilises veenmises. Kui tahame mõista oma igapäevaelu sotsiaalse keskkonna sõnumeid tervikuna ja nende sõnumite mõju meie väärtushinnangutele, hoiakutele ja käitumisele, siis verbaalsetest sõnumitest ei piisa. Peame uurima visuaalide keelt, ja mitte ainult illustratsiooni või verbaalse teksti tasandil, vaid kui kommunikatsioonikanalit, mis võib veenmise mõttes olla palju võimsam kui verbaalne keel. 


\section{Kirjandus}

Allison, Ron 1995. Cross-cultural factors in global advertising. - Jürgen Bolten (Ed.). CrossCulture - Interkulturelles Handeln in der Wirtschaft. Sternenfels: Verlag Wissenschaft \& Praxis, 92-101.

Blakesley, David 2006. Visual Rhetoric. http://www.cla.purdue.edu/dblakesley/visual/ (01.04.2006).

Braeutigam, Sven 2005. Neuroeconomics - from neural systems to economic behaviour. Brain Research Bulletin 67, 355-360.

Dahl, Øyvind 2001. Møter mellom mennesker. Interkulturell kommunikasjon. Oslo: Gyldendal.

Economist 2003. MRI's inside story. 369 (8353), 26-28.

Erk, Susanne; Spitzer, Manfred; Wunderlich, Arthtur P.; Galley, Lars; Walter, Henrik 2002. Cultural objects modulate reward circuitry. - Neuroreport 13 (18), 2499-2503.

Holt, Douglas, B. 2004. How Brands Become Icons: The Principles of Cultural Branding. Harvard Business School Press.

Larsen, Val; Luna, David; Peracchio Laura A. 2004. Points of view and pieces of time: A taxonomy of image attributes. - Journal of Consumer Research 31, 102-111.

Lee, Nick; Broderick, Amanda J.; Chamberlain, Laura (2007). What is 'neuromarketing'? A discussion and agenda for future research. - International Journal of Psychophysiology, 63 (2), 199-204.

Lester, Paul 1999. Visual Communication. Images with Messages. Belmont CA: Wadsworth.

Li, Zhenyi 2001. Cultural impact on international branding. A case of marketing Finnish mobile phones in China. Doctoral dissertation. University of Jyväskylä.

McClure, Samuel M.; Li, Jian; Tomlin, D.; Cypert, Kim S.; Montague Latané M.; Montague, Read P. 2004. Neural correlates of behavioral preference for culturally familiar drinks. - Neuron 44, 379-387.

Jaakko Lehtose (Jyväskylä Ülikool) uurimisvaldkondadeks on organisatsiooni suhtekorraldus ja ühiskondlik vastutus, imago ja kollektiivi-identiteet, Soome kuvand, kommunikatsioon ja rahvusvahelistumine, kommunikatsiooni eetika.

jaakko.lehtonen@jyu.fi 


\section{MORE THAN WORDS}

\section{Jaakko Lehtonen}

University of Jyväskylä

This article wants to encourage applied linguists to focus on research in visual communication, not as illustration of verbal texts but as 'texts' in the language of visuals. The significance of visuals in communication is grounded with recent findings in studies using the dynamic MRI methodology.

Keywords: literacy, advertisement, persuasion, visual language, visual, MRI 